\title{
Opioid use disorder in pregnancy
}

\author{
Anshula Ambasta MD MPH, Mary Malebranche MD MA
}

Cite as: CMAJ 2019 September 23;191:E1057. doi: 10.1503/cmaj.190391

1

In parallel with the opioid epidemic in the general population, opioid use and associated opioid use disorders in pregnancy are rising

According to an administrative database study, ${ }^{1}$ the number of infants born in Ontario to women given a diagnosis of opioid use disorder (including prescription and nonprescription opioids) increased 16-fold from 46 in 2002 to 761 in 2014.

2

Guidelines support universal screening for drug use, including opioids, by prenatal care providers

Screening based on perceived risk factors misses cases and perpetuates stigma and stereotyping. ${ }^{2,3} \mathrm{~A}$ validated screening tool should be used at first prenatal assessment and then periodically when clinically relevant (Box 1). ${ }^{2}$

\section{Opioid-agonist therapy is the standard of care for opioid use}

disorders in pregnancy, alongside counselling and mental health supports ${ }^{2,3}$

The cycle of opioid withdrawal and intoxication in pregnancy, in addition to often coincident social instability, can be harmful to both mother and fetus. Pregnant women with an opioid use disorder should be offered timely access to opioid agonist therapy. ${ }^{2,3}$ Both methadone and buprenorphinenaloxone are safe in pregnancy. ${ }^{3}$ Care providers should familiarize themselves with local resources to ensure timely linkage to prenatal care, addiction counselling and social supports.

Neonatal opioid withdrawal syndrome is best managed by keeping mothers and infants together after delivery

Compared with care in the neonatal intensive care unit, rooming-in is associated with stronger mother-infant bonding, higher likelihood of breastfeeding, reduced pharmacologic treatment and shorter length of stay. ${ }^{4}$ Breastfeeding should be encouraged in women who are stable on opioid agonist therapy, for whom there are no concerns about ongoing drug use postpartum..$^{2,3}$

\section{Ongoing support in the postpartum period is essential}

A recent study found that women with opioid use disorders are at increased risk of fatal overdose in the first year postpartum. ${ }^{5}$ Ongoing medical and social supports through primary care providers and opioid agonist therapy prescribers should remain stable postpartum to reduce this risk and support the well-being of mother and baby. 2,5
Box 1: Validated screening tools for prenatal opioid use disorder ${ }^{2}$

- 4 P's for Substance Abuse: Parents, Partner, Past, Present)

- National Institute on Drug Abuse (NIDA) Quick Screen

- CRAFFT (Car, Relax, Alone, Forget, Friends and Trouble) questionnaire: substance abuse screen for adolescents and young adults (for women aged 26 years or younger)

\section{References}

1. Brogly SB, Turner S, Lajkosz K, et al. Infants born to opioiddependent women in Ontario, 2002-2014. J Obstet Gynaecol Can 2017;39:157-65.

2. Committee on Obstetric Practice, et al. ACOG Committee Opinion, No. 711: opioid use and opioid use disorder in pregnancy. Obstet Gynecol 2017;130:e81-94.

3. Abrahams R, Ryan A, Berkman J, et al. Treatment of opioid use disorder during pregnancy: guideline supplement. Vancouver: British Columbia Centre on Substance Use; Victoria: BC Ministry of Health; Vancouver: Perinatal Services BC; 2018. Available: www.bccsu.ca/wp-content/uploads/2018/06/ OUD-Pregnancy.pdf (accessed 2019 May 19)

4. MacMillan KDL, Rendon CP, Verma K, et al. Association of rooming-in with outcomes for neonatal abstinence syndrome: a systematic review and meta-analysis. JAMA Pediatr 2018;172:345-51.

5. Schiff DM, Nielsen T, Terplan M, et al. Fatal and nonfatal overdose among pregnant and postpartum women in Massachusetts. Obstet Gynecol 2018;132:466-74.

\section{Competing interests: None declared.}

This article has been peer reviewed.

Affiliations: Cumming School of Medicine and O'Brien Institute of Public Health, University of Calgary, Calgary, Alta.

Correspondence to: Anshula Ambasta, aambasta@ucalgary.ca 